\title{
A NOTE ON THE DIMENSIONS OF THE BRONCHIAL TREE
}

\author{
BY
}

\author{
C. H. BARNETT \\ From the Anatomy Department, St. Thomas's Hospital Medical School, London
}

(RECEIVED FOR PUBLICATION AUGUST 28, 1956)

As Hilding (1949) states, "It is generally assumed that the total cross-sectional area of the [bronchial] tree increases progressively with each successive branching." Having studied the bronchial tree post mortem by slitting open the bronchi and measuring their calibre, Hilding himself believes that the total cross-sectional area of the tree remains almost constant until bronchi of diameter $1.5 \mathrm{~mm}$. are reached. In other words, he regards the respiratory tract not as an everwidening funnel but as a cylinder from the end of which sprout the bronchioles and the respiratory units.

The angle at which the daughter bronchi diverge after a bifurcation is of theoretical interest, and there has been much dispute as to the exact mode of branching (summarized by Miller, 1937). Relatively little attention, however, has been paid to the statement of Ewart (1889) that in the proximal part of the bronchial tree "it is an almost invariable rule that of two diverging bronchi the smaller one diverges most from the direction of the parent tube."

In the present study an attempt is made to confirm the observations of Hilding and Ewart, using "marco" resin casts of a normal adult bronchial tree (Tompsett, 1952). The theoretical implications of their observations will be discussed.

\section{Material AND Methods}

For measuring the cross-sectional area of the bronchial tree, one of a series of resin casts prepared by Dr. D. Tompsett was selected in which the lower part of the trachea and all the main bronchi had been well filled, the degree of inflation corresponding to the state of full inspiration. The diameters of the bronchi were measured by callipers to the nearest half millimetre, and the angles at which they forked were found by matching a small pair of graduated dividers alongside them. Less complete measurements were made of two other bronchial casts; since all three groups of figures were in general agreement details of only one cast are recorded here.

A number of bronchi were found to give off very small side branches almost at right angles, without themselves diminishing appreciably in diameter. In enumerating the bifurcations of the bronchial tree these minute side branches-examples of the "wide angle divisions" described by Hayward and Reid (1952)-have been disregarded.

\section{Results}

The following cross-sectional areas were obtained :

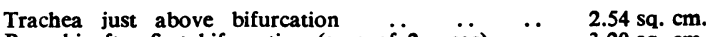
Bronchi after first bifurcation (sum of 2 areas) $\quad . . \quad 3.20 \mathrm{sq} . \mathrm{cm}$. Bronchi after second bifurcation (sum of 4 areas) .. $\quad 3.30 \mathrm{sq} . \mathrm{cm}$. Bronchi after third bifurcation (sum of 8 areas) $\ldots \quad 6.50 \mathrm{sq} . \mathrm{cm}$.

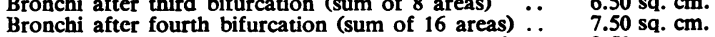
Bronchi after fifth bifurcation (sum of 32 areas) .. $9.50 \mathrm{sq} . \mathrm{cm}$.

The cross-sectional area thus increases up to the fifth bifurcation by a factor of about 1.3 at each generation of bronchi. To find whether the same rate of increase obtains in the smaller bronchi, 35 sites of bifurcation near the periphery of the cast were chosen at random and the crosssectional areas of the parent and daughter bronchi were calculated. The mean factor of increase was 1.39 (S.D. \pm 0.31 ). The number of bifurcations before bronchi of $1.5 \mathrm{~mm}$. diameter were reached was estimated to be eight (average of 25 observations). From these figures the cross-sectional area of the bronchial tree at the level of bronchi of diameter $1.5 \mathrm{~mm}$. was calculated to be approximately $25 \mathrm{sq} . \mathrm{cm}$.

The angle of branching of the larger bronchi was measured, and in the proximal part of the bronchial tree Ewart's statement was confirmed that the wider daughter branch diverged less than the narrower from the original direction of the parent bronchus. This rule did not apply consistently beyond the fifth generation of bronchi, however, and in seven out of the 50 smaller bifurcations measured the wider daughter branch diverged more than the narrower.

\section{Discussion}

The present estimates of the cross-sectional area of the bronchial tree at different levels conflict somewhat with the findings of Hilding (1949). 
This discrepancy is doubtless due to the fact that the bronchial cast corresponded to a fully inflated lung, whereas Hilding's measurements were made on collapsed bronchial trees: the marked change in calibre of the smaller bronchi during deep respiration has been emphasized by Macklin (1932), Fowler (1948), and Rossier and Bühlmann (1955). The bronchial tree in full inspiration may be likened to a very gradually expanding funnel, while in full expiration it may be represented by a cylinder as Hilding suggested. It follows that the calibre of the various branches is as small as is compatible with an adequate airway, for if the bronchi were any narrower the total cross-sectional area would fall below that of the trachea itself.

The significance of Ewart's rule of bronchial bifurcation becomes clear by reference to a specific example. In Fig. 1 the points $A, B$, and $C$ form an equilateral triangle of side length $X$.

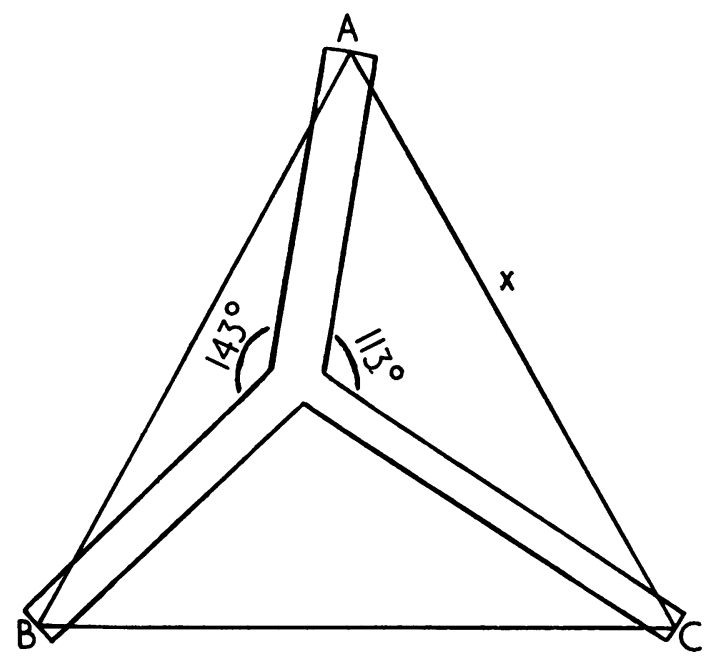

Fig. 1

From $A$, a main bronchus of length $\frac{1}{2} x$ passes in the general direction of $\mathrm{BC}$ before dividing into two daughter bronchi which carry respectively two-thirds and one-third of the air in the main bronchus. It can be calculated that, if the wall thickness is uniform throughout, the system will occupy the smallest possible space when the wider daughter bronchus diverges at an angle of approximately $143^{\circ}$ and the narrower daughter bronchus at a more acute angle, $113^{\circ}$. In general, therefore, if the volume of the whole bronchial tree is to be minimal, the wider daughter bronchus must diverge less than the narrower at all the bifurcations.

The observations of both Hilding and Ewart can thus be related to the necessity, in an efficient lung, क for the volume of the bronchial tree to be as small . as possible, thus allowing ample space for the actual respiratory tissue.

The same consideration may account for the $\vec{x}$ remarkably constant pattern of the bronchopul- ${ }_{\vec{N}}$ monary segments of the human lung. Despite the $N$ frequency of variations in one or other segment (Boyden, 1955), the same basic plan can always be $v$ recognized. One may suggest as a working hypo- $\mathrm{O}$ thesis that this plan represents the perfect mode of bronchial branching, calling for the least possible $c$

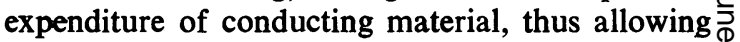
the greatest possible space for the essential respiratory tissue within a lung of given size. In $\mathcal{G}$ theory, any departure from the standard pattern. would necessarily produce a less effective lung. Minor variations would not reduce the respiratory efficiency to an appreciable extent, however, and therefore one would not expect natural selec- $\not$ tion to have imposed upon the species a com- $\stackrel{\AA}{\circ}$ pletely rigid pattern of bronchial subdivision.

\section{SUMMARY}

Two rules governing the mode of branching of the bronchial tree, suggested by Ewart (1889) and Hilding (1949), have been confirmed by measuring resin casts. Both can be correlated with the neces- -0 sity for the conducting portion of the lung to 3 . occupy as small a volume as possible, thus allowing ample space for the respiratory tissue. The same considerations may account for the con-응 stancy of the pattern of bronchial subdivision.

I am indebted to Dr. D. H. Tompsett and Dr. S. Engel for their helpful interest in this work, and too Professor D. V. Davies for criticism and advice.

\section{REFERENCES}

Boyden E. A. (1955). Segmental Anatomy of the Lungs. McGrawHill, New York.

Ewart, W. (1889). The Bronchi and Pulmonary Blood-vessels, p. 35. Churchill, London.

Fowler, W. S. (1948). Amer.JJ. Physiol., 154, 405.

Hayward, J., and Reid, L. McA. (1952). Thorax, 7, 89.

Hilding, A. C. (1949). Acta oto-laryng. (Stockh.), 37, 138.

Macklin, C. C. (1932). Amer. Rev. Tuberc., 25, 393. Miller, W. S. (1937). The Lung, pp. 21-23. Thomas, Springfield

Rossier, P. H., and Bühlmann, A. (1955). Physiol. Rev., 35, 860

Tompsett, D. H. (1952). Thorax, 7, 78. 